A N N A L E S Annales de Bretagne et des Pays de l'Ouest

Comptes du duché de Bretagne. Les comptes, inventaires et exécution des testaments ducaux, 1262-1352

\title{
Amaury Chauou
}

\section{(2) OpenEdition}

9 Journals

\section{Édition électronique}

URL : https://journals.openedition.org/abpo/4188

DOI : $10.4000 / a b p o .4188$

ISBN : 978-2-7535-7720-6

ISSN : 2108-6443

Éditeur

Presses universitaires de Rennes

Édition imprimée

Date de publication : 18 décembre 2018

Pagination : 175-176

ISBN : 978-2-7535-7718-3

ISSN : 0399-0826

\section{Référence électronique}

Amaury Chauou, «Comptes du duché de Bretagne. Les comptes, inventaires et exécution des testaments ducaux, 1262-1352 », Annales de Bretagne et des Pays de l'Ouest [En ligne], 125-4 | 2018, mis en ligne le 18 décembre 2018, consulté le 03 mars 2022. URL : http://journals.openedition.org/abpo/4188 ; DOI https://doi.org/10.4000/abpo.4188 
Jones, Michael, Charon, Philippe (dir.), Comptes du duché de Bretagne. Les comptes, inventaires et exécution des testaments ducaux, 1262-1352, Rennes, PUR/Société d'histoire et d'archéologie de Bretagne, coll. "Sources médiévales de l'histoire de Bretagne ", 2017, 512 p. Préface d'Yves Coativy.

L'excellente collection des Sources médiévales de l'histoire de Bretagne repose sur un audacieux postulat : la connaissance de la Bretagne médiévale, pour la période antérieure à la guerre de Succession de Bretagne (1341-1364), se heurte moins à une absence dramatique de documents historiques qu'à leur difficulté d'appréhension, leur éparpillement et leur caractère lacunaire. C'est ce que démontre fort à propos ce beau volume, qui vient enrichir une collection de publications déjà substantielles (Cartulaire de Saint-Guénolé de Landévennec, Cartulaire de Saint-Melaine de Rennes, entre autres).

Le point de départ est fourni par un constat réaliste : contrairement aux chroniques et autres sources narratives, les comptes publics ont longtemps été négligés par les historiens français. Non pas que leur étude ait été inexistante : la Bourgogne, par exemple, a fourni d'extraordinaires séries aux spécialistes des finances ducales. Mais par comparaison, les comptes royaux ou ceux des autres principautés françaises sont des parents pauvres. Dans le cas breton, le problème a été aggravé par les publications quelquefois fautives d'abrégés de comptes édités par les Mauristes, dom Lobineau puis dom Morice. Il a fallu le goût pour les " monuments » de l'histoire de Bretagne, à la fin du XIx ${ }^{\mathrm{e}}$ siècle (La Borderie), puis, après la Deuxième Guerre mondiale, les études plus érudites de Barthélemy-Amédée Pocquet du Haut-Jussé et Yves Renaudin ("Les domaines des ducs de Bretagne. Leur administration du $\mathrm{XIII}^{\mathrm{e}}$ au XVe siècle ", thèse inédite de l'École des Chartes, 1957), pour que ces documents soient pleinement mis en lumière, avant que Jean Kerhervé, dans sa thèse magistrale, n'en tire la grande étude d'histoire sociale, politique et financière qui manquait.

Dans le présent ouvrage, Michael Jones et Philippe Charon, déjà à pied d'œuvre pour l'édition dans la même collection de la thèse de $\mathrm{H}$. Guillotel consacrée aux Actes des ducs de Bretagne (944-1148), se concentrent sur le matériau des comptes, inventaires de succession et exécutions de testaments bretons étendus de 1262 à 1352, qu'ils éditent dans leur intégralité et dans le respect des préconisations de l'École des Chartes. Ces documents se répartissent en neuf sections : abrégés de comptes ducaux (1262-1275); recettes de l'exécution du testament de Jean I ${ }^{\text {er }}$ (12871291); créances et recettes dues à Jean II (1300-1303); inventaire des monnaies et objets précieux déposés dans La Tour neuve de Nantes (1303); dépenses de l'hôtel de Jean II (1305); exécution testamentaire de Jean II (1305-1323); inventaire des monnaies trouvées au trésor de la cathédrale de Nantes après la mort de Jean III (1341); comptes de Pierre Molin le jeune, receveur dans la vicomté de Limoges (1344-1347); comptes d'Alain de Guillemot, châtelain de Touffou (1348-1352). Environ la moitié de ce corpus conservé majoritairement sur des rouleaux de parchemin est inédite. L'ensemble est complété par un glossaire, deux index (noms des lieux et des personnes d'un côté, matières de l'autre), un répertoire des sources et une bibliographie, de même que par un jeu de huit cartes et seize planches en couleur, précédés par une riche introduction de Michael Jones.

Il ressort que la Bretagne, malgré les " effondrements documentaires " de la guerre de Succession du duché, des guerres de Religion ou de la Révolution française, a bien participé, avec un léger retard, et selon une évolution plus simple, de la centralisation et de la sophistication croissantes des pratiques comptables repérables par ailleurs en France durant la "révolution de l'écrit " du XIII et du siècle suivant, mais que cette " bureaucratisation " émergente est difficile à suivre 
en raison des lacunes documentaires. En particulier, l'inspiration de modèles existants, vraisemblablement pris du côté de l'Échiquier de Westminster dans le cas du plus vieil abrégé de comptes ducaux connus (1262), ou de celui des institutions capétiennes, montre un souci de technicité comparable à ce qui se retrouve dans les grandes cours européennes. L'essor d'un milieu de gens de finances ("gens de nos comptes ", selon un document des environs de 1300) est aussi perceptible, par étoffement des rangs des quelques clercs que l'on croise au XIII ${ }^{\mathrm{e}}$ siècle. Le remarquable dossier inédit de l'exécution testamentaire de Jean II, mortellement blessé à Lyon par l'écroulement accidentel d'un mur lors du couronnement du pape Clément V (novembre 1305), révèle la complexité de la tâche en raison de la nature des largesses opérées par le défunt (1000 § aux frères des Carmes de Ploërmel qui accueillent sa sépulture, 6000 \& aux pauvres de Bretagne!), de la longueur des procédures (1305-1323), de la pluralité des intervenants et du nombre des déplacements inhérents. Ce dossier fourmille d'indications rarement connues pour la Bretagne : sur le coût des funérailles ducales (pièce xxxII), celui de l'exécution du tombeau de Jean II à Ploërmel (pièce XXXVI). Il est l'occasion de publier un état descriptif saisissant des aumônes distribuées en deniers, tuniques et paires de souliers aux pauvres du seul diocèse de Rennes, paroisse par paroisse (p. 298-303). Au passage apparaissent les richesses accumulées à la Tour du château de Suscinio, ou à la Tour neuve du château de Nantes, de même que les noms des receveurs et trésoriers qui les manipulent. Ainsi, on peut suivre à la trace ce Rolland Le Lombard, un habile Italien qui s'attache à la cour ducale au point d'en obtenir vraisemblablement la première commission connue en matière de gestion comptable, et qui prospère sous les ducs de la Maison de Dreux en compagnie d'autres officiers de finance d'origine bretonne.

Au total, la moisson est prolifique : histoire financière, institutionnelle, sociale, politique, économique, religieuse, culturelle, histoire locale... Des pans entiers de l'histoire bretonne ressortent mieux éclairés du maniement de cette édition majeure. Nul doute qu'elle en appellera d'autres (il reste beaucoup à faire sur les comptes ducaux des XIV et XV siècles et sur les comptes seigneuriaux). D'ores et déjà, l'on ne peut que remercier les éditeurs pour les avancées que représente ce travail où l'érudition la plus sûre croise la meilleure mise en perspective historique.

Amaury CHAUOU

GuILlET, Bertrand, ARMiDE, Aurélien (dir.), Le château des ducs de Bretagne entre grandeur et renouveau. Huit siècles d'histoire, Nantes, Éditions du château des ducs de Bretagne/Rennes, PUR, 2016, 624 p.

L'édition de beaux livres sur Nantes a le vent en poupe! Après les magnifiques ouvrages publiés en 2013, l'un à Strasbourg consacré à la cathédrale, l'autre à Rennes et évoquant rien moins que la ville, au sens très large, voici " la première monographie du château des ducs de Bretagne " (p. 12). Cette affirmation n'a rien de présomptueux, non pas que les travaux sur cet illustre monument soient rares ou anciens, mais il fallait absolument les amplifier en présentant les recherches archéologiques et historiques récentes, ainsi que les travaux de restauration. Le choix d'un grand format permet d'offrir au lecteur, ravi, de somptueuses illustrations, souvent en pleine page, tant de documents d'archives, de représentations graphiques que de photographies anciennes ou modernes. Beau livre ne signifie pas ici vacuité du discours : si l'objet final peut agréablement adorner un salon où il serait innocemment 